\title{
Classification of individuals with dyslipidaemia controlled by statins according to plasma biomarkers of oxidative stress using cluster analysis
}

\author{
Patrícia B. Botelho ${ }^{1}$, Cyntia O. Fioratti ${ }^{1}$, Dulcinéia S. P. Abdalla ${ }^{2}$, Marcelo C. Bertolami ${ }^{3}$ \\ and Inar A. Castro ${ }^{4 *}$ \\ ${ }^{1}$ Department of Food and Experimental Nutrition, Faculty of Pharmaceutical Sciences, University of São Paulo, \\ Av. Lineu Prestes 580 B14, 05508-900 São Paulo, SP, Brazil \\ ${ }^{2}$ Department of Clinical and Toxicological Analysis, Faculty of Pharmaceutical Sciences, University of São Paulo, \\ Av. Lineu Prestes 580 B14, 05508-900 São Paulo, SP, Brazil \\ ${ }^{3}$ Dante Pazzanese Institute of Cardiology, Av. Dr Dante Pazzanese, 500 São Paulo, SP, Brazil \\ ${ }^{4}$ Department of Food and Experimental Nutrition, Faculty of Pharmaceutical Sciences, University of São Paulo, \\ Av. Lineu Prestes 580 B14, 05508-900 São Paulo, SP, Brazil \\ (Received 2 June 2009 - Revised 21 July 2009 - Accepted 22 July 2009 - First published online 14 September 2009)
}

Oxidative stress is a physiological condition that is associated with atherosclerosis, and it can be influenced by diet. Our objective was to group fifty-seven individuals with dyslipidaemia controlled by statins according to four oxidative biomarkers, and to evaluate the diet pattern and blood biochemistry differences between these groups. Blood samples were collected and the following parameters were evaluated: diet intake; plasma fatty acids; lipoprotein concentration; glucose; oxidised LDL (oxLDL); malondialdehyde (MDA); total antioxidant activity by 2,2-diphenyl1-picrylhydrazyl (DPPH) and ferric reducing ability power assays. Individuals were separated into five groups by cluster analysis. All groups showed a difference with respect to at least one of the four oxidative stress biomarkers. The separation of individuals in the first axis was based upon their total antioxidant activity. Clusters located on the right side showed higher total antioxidant activity, higher myristic fatty acid and lower arachidonic fatty acid proportions than clusters located on the left side. A negative correlation was observed between DPPH and the peroxidability index. The second axis showed differences in oxidation status as measured by MDA and oxLDL concentrations. Clusters located on the upper side showed higher oxidative status and lower HDL cholesterol concentration than clusters located on the lower side. There were no differences in diet among the five clusters. Therefore, fatty acid synthesis and HDL cholesterol concentration seem to exert a more significant effect on the oxidative conditions of the individuals with dyslipidaemia controlled by statins than does their food intake.

Oxidative stress: Lipoproteins: Fatty acids: Diet

Oxidative stress can be defined as the disruption of redox signalling and control ${ }^{(1)}$. Many studies support the important role that oxidative stress plays in the development of CVD, including atherosclerosis ${ }^{(2-4)}$. LDL (LDL cholesterol) are preferentially deposited in the vascular wall, where they are oxidised as a consequence of oxidative stress ${ }^{(3)}$. This process occurs during the early stages of the endothelial dysfunction that result in atherosclerotic lesions and the development of foam cells ${ }^{(5)}$. Therefore, the oxidation of lipids and proteins that are present in the LDL cholesterol structure has been considered to be one of the major risk factors for the progression of atherosclerosis ${ }^{(2,6,7)}$. For this reason, oxidative stress can be especially hazardous to individuals who have a high LDL cholesterol concentration or who have an LDL cholesterol concentration that is controlled by drugs, such as statins.

Several factors can influence oxidative status and oxidative susceptibility. The antioxidant defence can be improved by some nutrients in the diet, which are able to protect the organism against many causes of early death and increase survival, especially under suboptimum conditions ${ }^{(8)}$. The consumption of a diet rich in natural antioxidants contributes to reduce postprandial oxidative status and has been associated with prevention from and/or the treatment of atherosclerosis ${ }^{(2,9,10)}$.

One of the principal limitations in human oxidative stress research is the lack of a specific biomarker ${ }^{(4,11,12)}$. As a result, assessing oxidative stress remains a challenge ${ }^{(13)}$. In addition, since studies with human subjects cannot be invasive, almost all experiments are performed on blood or urine samples. There is no consensus about which biomarker would be the most appropriate to evaluate in vivo oxidation. Recently, Capitani et al. ${ }^{(14)}$ have proposed the use of multivariate statistical techniques to classify natural and synthetic compounds according to their antioxidant activity, which was measured by five different methodologies. One of these

Abbreviations: DPPH, 2,2-diphenyl-1-picrylhydrazyl; FRAP, ferric reducing ability power; MDA, malondialdehyde; oxLDL, oxidised LDL; PC, principal component.

* Corresponding author: Professor Inar Alves Castro, fax +55 11 38154410, email inar@usp.br 
techniques, which is known as principal component (PC) analysis, reduces the original number of variables to a smaller number of new, uncorrelated variables (PC) based upon their linear correlations. These statistical tools make it possible to separate individuals according to their oxidation profile, as measured by more than three biomarkers, and this dispersion can be graphically visualised. In addition, cluster analysis, another multivariate technique, can be used to group individuals according to their similarities and differences with regard to selected biomarkers that were measured at the same time. Thus, the objective of the present study was to apply a multivariate statistical approach to group individuals with dyslipidaemia controlled by statins according to four oxidative biomarkers and to evaluate the diet pattern and blood biochemistry differences between these groups.

\section{Methods}

\section{Chemicals}

All reagents were purchased from Sigma Chemical Co. (St Louis, MO, USA), Merck (Darmstadt, Germany) and Invitrogen Corporation (Carlsbad, CA, USA). All other reagents used in the experiments were of analytical grade. The aqueous solutions were prepared by using ultra-pure Milli-Q water (Millipore Ind. Com. Ltd, Jurubatuba, SP, Brazil), while the organic solvents were HPLC grade.

\section{Subjects}

Subjects were recruited from the patient data bank at the Dante Pazzanese Institute of Cardiology. From the hospital database containing 1056 patients, eighty-two individuals, including both males and females, were recruited to participate in the study. The inclusion criteria included age between 30 and 80 years old, BMI between 18.5 and $29.9 \mathrm{~kg} / \mathrm{m}^{2}$ and taking statins (simvastatin or atorvastatin) at doses ranging from 10 to $80 \mathrm{mg} / \mathrm{d}$ for at least 6 months. The exclusion criteria were pregnant or breast feeding, diabetes, kidney disease, endocrine disease, liver disease, a personal history of myocardial infarction or stroke and hormone treatment for menopause. All volunteers were instructed to maintain their normal daily routines and food intake throughout the study. Out of the eighty-two individuals who were initially recruited, fifty-seven participated in the study. The remaining twenty-five volunteers dropped out the study because they did not have their blood collected on time. At the first meeting, the participants recorded their usual dietary intake, gave an overnight fasting blood sample and had their body weight and waist/hip circumference taken. Dietary intake was assessed with the use of a 3-d food register (two workdays and one weekend day) at the beginning and after $30 \mathrm{~d}$. The intake during the test period was calculated as the mean value of the 6-d dietary register. The nutrient composition of the diets was assessed by using the Nutriquanti ${ }^{\circledR}$ software, which is based on the United States Department of Agriculture database $^{(15)}$. Body weight was measured using a digital scale with an accuracy of $0.1 \mathrm{~kg}$. The subjects' heights were measured with a stadiometer, and waist circumference was expressed in $\mathrm{cm}$ and measured midway between the lowest rib margin and iliac crest to the nearest $1 \mathrm{~mm}$ in a standing position. Hip circumference was measured on the widest part of the buttocks. BMI was calculated as body weight divided by squared height $\left(\mathrm{kg} / \mathrm{m}^{2}\right)$. Blood samples were drawn from the forearm vein into EDTA-treated and plain Vacutainer tubes (Becton Dickinson, Rutherford, NJ, USA), which were immediately centrifuged at $1600 \mathrm{~g} / 10 \mathrm{~min}$ at $4^{\circ} \mathrm{C}$ (Hitachi, CF-15R, Tokyo, Japan). Plasma and serum samples were divided into $1.5 \mathrm{ml}$ Eppendorf tubes and immediately frozen under liquid nitrogen. Five microlitres of cocktail containing 4 mM-butylated hydroxytoluene, $200 \mathrm{~mm}$-phenylmethanesulphonylfluoride, $400 \mathrm{~mm}$-benzamidine and $40 \mu \mathrm{g} / \mathrm{ml}$ aprotinine was added to $1 \mathrm{ml}$ of the samples that were selected for the measurement of LDL-cholesterol oxidation (oxLDL). In the laboratory, all samples were transferred from the liquid nitrogen tank to an ultra-freezer and kept at $-80^{\circ} \mathrm{C}$ until analysis. Except in the case of oxLDL determination, all samples were thawed only one time. Plasma samples were analysed enzymatically for total cholesterol (Liquiform Cat. 76, using cholesterol esterase, cholesterol oxidase and peroxidase), HDL cholesterol (Cat. 13, using precipitation with phosphotungstenic acid and $\mathrm{MgCl}_{2}$ ) and TAG (GPO-ANA, Cat. 59, using glycerol 3-phosphate oxidase). LDL cholesterol was calculated by the Friedwald equation $^{(16)}$ :

$$
\begin{aligned}
\text { LDL cholesterol }= & \text { total cholesterol }- \text { HDL cholesterol } \\
& -(\mathrm{TAG} / 5) .
\end{aligned}
$$

Glucose was carried out using the glucose oxidase automatic glucose oxidase Trinder colorimetric assay (Glucose PAP Liquiform). All values were determined using a Micronal B-380 spectrophotometer (São Paulo, SP, Brazil). All these experiments were repeated $30 \mathrm{~d}$ after the first meeting.

\section{Plasma fatty acid composition}

Lipids were extracted from plasma $(1.0 \mathrm{ml})$ according to Folch et al. ${ }^{(17)}$ using a methanol-chloroform mixture as solvent. Fatty acids were esterified by the method of Hartman \& Lago ${ }^{(18)}$ and their composition was determined by GC (GC17A, Shimadzu, Kyoto, Japan; class CG equipped with autosampler and controlled by a software package, Class CG10). A capillary column (Supelcowax 10, Bellefonte, PA, USA; $30 \mathrm{~m} \times 0.25 \mathrm{~mm}$ inner diameter) was used for injection. Helium was used as carrier gas (flow rate: $1 \mathrm{ml} / \mathrm{min}$ ). The injector port and detector temperatures were 250 and $270^{\circ} \mathrm{C}$, respectively. The column temperature was increased stepwise $\left(1^{\circ} \mathrm{C} / \mathrm{min}\right)$ to a plateau $\left(225^{\circ} \mathrm{C}\right)$, which was kept for $10 \mathrm{~min}$. A standard mixture with thirty-seven fatty acid methyl esters (Sigma Chemical Co.) and a standard mixture containing nineteen components (Supelco, Inc.) were used to identify the peaks. Results were expressed as percentage of total fatty acid present. The peroxidability index of the lipids was calculated on basis of the number of methylene groups among the double bonds, according to the following equation reported by Hsu et al. ${ }^{(19)}$ :

$$
\begin{aligned}
\text { Peroxidability index }= & (\% \text { dienoic } \times 1)+(\% \text { trienoic } \times 2) \\
& +(\% \text { tetraenoic } \times 3)+(\% \text { pentaenoic } \times 4) \\
& +(\% \text { hexaenoic } \times 5) .
\end{aligned}
$$




\section{Blood total antioxidant activity (2,2-diphenyl-1-picrylhydrazyl} radical and ferric reducing ability power)

The measurement of total antioxidant activity was performed in serum and plasma samples by two methods: 2,2-diphenyl1-picrylhydrazyl radical (DPPH) and the ferric reducing ability power (FRAP). The DPPH method was carried out according to Chrzczanowicz et al. ${ }^{(20)}$ with some modifications. Serum $(100 \mu l)$ was mixed with $900 \mu l$ methanol, incubated for $2 \mathrm{~min}$ at room temperature and then centrifuged at $9500 \mathrm{~g}$ for $10 \mathrm{~min} / 4^{\circ} \mathrm{C}$ (Hitachi, CF-15R). Samples $(25.0 \mu \mathrm{l})$ of supernatant containing deproteinised serum were mixed with $5.0 \mu \mathrm{l} \mathrm{DPPH}$ solution $(10.0 \mathrm{mmol} / \mathrm{l}$ in methanol) and up to $1.0 \mathrm{ml}$ methanol. Absorbance at $517 \mathrm{~nm}$ was read after $30 \mathrm{~min}$ of incubation period at $20^{\circ} \mathrm{C}$, using a spectrophotometer (UV-Mini 1240, Shimadzu Corporation). Some samples received $25.0 \mu \mathrm{l}$ of methanol as a blank. All experiments were performed in triplicate and antioxidant activity was calculated according to percentage of inhibition $=\left(1-\left(A_{517}\right.\right.$ sample $/ A_{517} \quad$ blank $\left.)\right) \times 100 \%$. The FRAP method was performed as described by Benzie \& Strain ${ }^{(21)}$. This method measures the capacity of the sample to reduce the $\left[\mathrm{Fe}^{3+}-\mathrm{TPTZ}\right]$ complex to the $\left[\mathrm{Fe}^{2+}-\mathrm{TPTZ}\right]$ complex, which is blue in colour $(\lambda=593 \mathrm{~nm})$. FRAP reagents included $300.0 \mathrm{~mm}$-acetate buffer, $\mathrm{pH} 3.6,10.0 \mathrm{mM}$ $2,4,6$-tripyridyl-s-triazine dissolved in $40.0 \mathrm{mM}-\mathrm{HCl}$ and $20 \cdot 0 \mathrm{~mm}-\mathrm{FeCl}_{3} \cdot 6 \mathrm{H}_{2} \mathrm{O}$ solution in distilled water. The FRAP reagent was freshly prepared by mixing $25.0 \mathrm{ml}$ acetate buffer with $2.5 \mathrm{ml}$ 2,4,6-tripyridyl-s-triazine solution and $2.5 \mathrm{ml} \mathrm{FeCl} \cdot 6 \mathrm{H}_{2} \mathrm{O}$ solution. Briefly, $3.0 \mathrm{ml}$ fresh FRAP reagent was mixed with $100.0 \mu \mathrm{l}$ plasma, and the absorbance at $593 \mathrm{~nm}$ was read in the beginning $\left(\mathrm{Abs}_{\mathrm{T} 0}\right)$ and after $6 \mathrm{~min}$ $\left(\mathrm{Abs}_{\mathrm{T} 6}\right)$, which were both read against a reagent blank (Milli-Q water) at room temperature using a spectrophotometer (UV-Mini 1240, Shimadzu Corporation). The difference between the absorbance values $\left(\Delta A_{593 \mathrm{~nm}}\right)$ was calculated for each sample. Freshly prepared aqueous solutions of $\mathrm{Fe}^{2+}\left(\mathrm{FeSO}_{4} \cdot 7 \mathrm{H}_{2} \mathrm{O}\right)$ at $1000 \mu \mathrm{mol} / \mathrm{l}$ were used for expression of the results. Sample FRAP values were calculated as: $\left(\Delta A_{593 \mathrm{~nm}} \mathrm{sample} / \Delta A_{593 \mathrm{~nm}} . \mathrm{Fe}_{2} \mathrm{SO}_{4}\right.$ at $1000 \mu \mathrm{mol} / \mathrm{l}) \times 1000 \mu \mathrm{mol} / \mathrm{l}$. Thus, in both methods, the higher the percentage of inhibition or $\mathrm{Fe}_{2} \mathrm{SO}_{4} \mu \mathrm{mol} / \mathrm{l}$, the higher the total antioxidant activity.

\section{Oxidised-LDL measurement}

The plasma concentration of oxLDL was evaluated using sandwich ELISA, according to Faulin et al. ${ }^{(22)}$. Briefly, ninety-six-well flat-bottom polystyrene microtitre plates (Costar, Corning, Inc., Teterboro, NY, USA) were coated with $10 \mu \mathrm{g} / \mathrm{ml}$ anti-LDL $(-) 1 \mathrm{~A} 3 \mathrm{H} 2$ monoclonal antibody $\left(50.0 \mu \mathrm{l} /\right.$ well) overnight at $4^{\circ} \mathrm{C}$ in order to ensure antibody adherence in the plates. The plates were washed thrice with PBS, pH 7.4, containing $0.05 \%$ Tween $20(200 \mu \mathrm{l} /$ well). Free binding sites were blocked by the addition of $150 \mu \mathrm{l} /$ well PBS containing $2 \%$ non-fat dry milk, which was previously inactivated by heating $\left(100^{\circ} \mathrm{C}\right)$, and $0.01 \%$ Tween 20 for $1 \mathrm{~h}$ and $30 \mathrm{~min}$ at $37^{\circ} \mathrm{C}$, followed by washing as above. The standard or plasma (1:2000-1:10000, diluted in PBS containing $1 \%$ non-fat milk and $0.01 \%$ Tween 20) was added $(50 \mu \mathrm{l} / \mathrm{well})$ to the plates and again incubated for
$90 \mathrm{~min}$ at $37^{\circ} \mathrm{C}$. During this step, the oxLDL present in the samples binds to the antibody. Then, the plates were washed and incubated with $0.5 \mu \mathrm{g} /$ well of anti-LDL $(-)$ 2C7D5F10 monoclonal antibody that was conjugated to biotin for $1 \mathrm{~h}$ at $37^{\circ} \mathrm{C}$, forming the sandwich, [anti-LDL(-) $\left.1 \mathrm{~A} 3 \mathrm{H} 2\right]-$ [oxLDL]-[anti-LDL $(-)$ 2C7D5F10]. After incubation, the plates were again washed as described above. Then, $50.0 \mu \mathrm{l} /$ well streptavidin-conjugated horseradish peroxidase (Invitrogen Corporation) was added and incubated for $1 \mathrm{~h}$ at $37^{\circ} \mathrm{C}$, in order to link with the biotin. Washed plates were finally incubated with $50 \mu \mathrm{l}$ ortho-phenylenediamine, which was diluted in citrate phosphate buffer $\mathrm{pH} 5.3$ at $37^{\circ} \mathrm{C}$ for $15 \mathrm{~min}$. ortho-Phenylenediamine is a peroxidase substrate that produces a soluble end product with an orange-brown colour. The reaction was stopped by adding $2 \mathrm{M}-\mathrm{H}_{2} \mathrm{SO}_{4}$, and the absorbance was measured at $492 \mathrm{~nm}$ by spectrophotometry, using a microplate reader (Spectra Count Microplate Photometer, Packard Instruments Company, Downers Grove, IL, USA). A calibration curve was carried out in each plate, using $\operatorname{LDL}(-)$ extracted from human plasma by fast protein liquid chromatography as a standard $(0.625-20.000 \mu \mathrm{g} / \mathrm{ml})$. The results were expressed as $\mathrm{U} / \mathrm{l}$, with 1 unit representing $1.0 \mathrm{~g} / \mathrm{l}$ oxidised apo B.

\section{Plasma malondialdehyde concentration}

The MDA concentration in plasma EDTA samples was determined by reverse-phase HPLC, according to Cheng et al. ${ }^{(23)}$, by thiobarbituric acid derivatisation. Briefly, $50 \mu$ l plasma was added to $25 \mu 11 \%$ ethanol butylated hydroxytoluene, $425 \mu 1$ Milli-Q water and $750 \mu \mathrm{l}$ phosphoric acid. Tubes were vortexed for $10 \mathrm{~s}$ and boiled for $1 \mathrm{~h}$. Samples were cooled to room temperature using an ice bath, and $500 \mu l$ were transferred to an Eppendorf tube, to which $400 \mu$ l methanol + $100 \mu 11.0 \mathrm{~mol} \mathrm{NaOH}$ were added to extract the MDA-thiobarbituric acid adduct. The Eppendorf tubes were centrifuged at $14000 \mathrm{~g}$ for $5 \mathrm{~min}$ at $20^{\circ} \mathrm{C}$ (Hitachi, CF-15R), and the supernatant was transferred to vials. The chromatographic analysis was performed in an HPLC (Agilent Technologies 1200 series; Santa Clara, CA, USA) that was connected to a computer. The thiobarbituric acid-MDA conjugate derivative $(20 \mu \mathrm{l})$ was injected onto analytical column Phenomenex reverse-phase C18 $(250 \mathrm{~mm} \times 4.6 \mathrm{~mm} ; 5 \mathrm{~mm}$

- Phenomenex, Torrance, CA, USA) with pre-column LC8-D8 (Phenomenex AJ0-1287) and fluorometrically quantified at an excitation of $515 \mathrm{~nm}$ and an emission of $543 \mathrm{~nm}$. The HPLC pump delivered the isocratic mobile phase (60\% PBS (50 mmol, pH 6.0) and $40 \%$ methanol) at a flow rate of $1.0 \mathrm{ml} / \mathrm{min}$. A standard curve was prepared using MDA tetrabutylammonium salt at a concentration of $0 \cdot 5-5 \cdot 0 \mu \mathrm{mol}$.

\section{Ethics}

The present study was conducted according to the guidelines laid down in the Declaration of Helsinki, and all procedures involving human patients were approved by the Ethics Committee of the Pharmaceutical Science Faculty and of the Dante Pazzanese Institute of Cardiology. Written informed consent was obtained from all patients. 


\section{Statistical analysis}

Results were expressed as mean followed by pooled SD. Differences between the two blood collection times $\left(T_{0}\right.$ and $T_{30}$ ) were evaluated by Student's $t$ test for dependent variables, while the comparison between sex was evaluated by Student's $t$ test for independent variables. PC analysis was the multivariate technique that was applied to assess and separate the individuals ( $n$ 57) according to their oxidative conditions based upon the four biomarkers. The data matrix $(57 \times 4)$ for independent variables that are expressed in different units $(\mu \mathrm{mol} / 1$, unit/l, percentage of inhibition or $\mathrm{Fe}_{2} \mathrm{SO}_{4} \mu \mathrm{mol} / \mathrm{l}$ ) was prepared by adopting the biomarkers as columns and the individuals as rows. Analyses were based on correlation, and variances were computed as sums of squares/ $(n-1)$. Eigenvalues higher than 1.0 were adopted in order to present the projection of the individuals on the factor plane $(1 \times 2)$. Tree-clustering analysis was used to group the individuals according to their similarities based upon the four biomarkers. This analysis was based on Ward's method and Euclidean distances, using the standardised matrix. Main-effects ANOVA followed by Tukey's honestly significantly different post hoc test was applied to evaluate the differences between the five selected clusters, which included sex and age as covariates. Homogeneity of variances was checked by the Hartley test. A $P$ value $<0.05$ was considered to be significant. The statistical analyses were performed using STATISTICA 7.1 software (Statsoft, Inc., Tulsa, OK, USA).

\section{Results}

The oxidative biomarkers, anthropometric measures, cholesterol, TAG, glucose concentration, lipoprotein concentration and the dietetic pattern in terms of macro- and micronutrients were all evaluated at the start of the study and after $30 \mathrm{~d}$ (Tables 1 and 2). Only FRAP and carbohydrate intake showed a statistical difference between the two time points. In the oxLDL measurements, samples were evaluated only after $30 \mathrm{~d}$.
The comparison of the data that were obtained in the present study against the values reported in the literature showed that the MDA concentration of the individuals with dyslipidaemia controlled by statins was higher $(P<0 \cdot 001)$ than the reference value for normolipidaemic individuals. The FRAP and DPPH results were also statistically lower $(P<0 \cdot 001)$ when compared with the mean reference pattern. Total cholesterol, TAG and LDL cholesterol mean concentrations were below the borderline values that have been recommended by the National Cholesterol Education Program ${ }^{(24)}$, which demonstrates the effect of statin treatment on the control of dyslipidaemia in these individuals. The HDL cholesterol concentration was below to the borderline value, and the glucose concentration could be considered to be indicative of a pre-diabetic condition for this population. With regard to the nutrient intake, with the exception of $\mathrm{Na}$ and ascorbic acid, all micronutrients were below the dietary reference intakes ${ }^{(25)}$, taking into account the range mean values that have been recommended for women and men. Males showed a higher total antioxidant activity (FRAP and DPPH) than females, although there were no differences for the MDA and oxLDL values between the two groups (Table 3). In addition, males showed lower linoleic acid, PUFA and HDL cholesterol concentration than females.

The mean values of all parameters that were obtained from the fifty-seven individuals, including both males and females, were applied in the multivariate statistical analysis. First, PC analysis was applied to reduce the original four variables to a lower number of uncorrelated components. The three PC that were selected here could explain $94 \%$ of the total variation. Taking into account eigenvalues greater than one, the individuals were separated in the first PC (Fig. 1) by their total antioxidant activity that was measured in plasma and serum (FRAP: +0.92 and DPPH: +0.93 ), separated in the second $\mathrm{PC}$ by their oxidation that was measured by MDA $(+0.74)$ and oxLDL $(+0.70)$ and separated in the third $\mathrm{PC}$, both above and below the plane, also by their oxidation status measured by MDA (+0.67) and oxLDL (-0.69), using opposite signals.

Table 1. Clinical and metabolic parameters of the subjects measured at the beginning and after $30 \mathrm{~d}$

(Mean values and pooled standard deviations)

\begin{tabular}{|c|c|c|c|c|c|c|c|}
\hline Variables & $T_{0}$ & $T_{30}$ & Mean ( $n 57)$ & Pooled SD & $P^{*}$ & CV (\%) & Reported values \\
\hline \multicolumn{8}{|l|}{ Oxidative biomarkers } \\
\hline $\operatorname{MDA}(\mu \mathrm{mol} / \mathrm{l})$ & 1.36 & 1.42 & 1.40 & 0.36 & 0.25 & $26 \cdot 00$ & $1.00^{(28)}$ \\
\hline FRAP $(\mu \mathrm{mol} / \mathrm{l})$ & $912 \cdot 00$ & $855 \cdot 00$ & 885.00 & 177 & $<0.001$ & $20 \cdot 00$ & $638-1634^{(21)}$ \\
\hline DPPH (\% of inhibition) & 4.5 & $4 \cdot 5$ & $4 \cdot 5$ & $1 \cdot 3$ & 0.839 & 29 & $5 \cdot 0-15 \cdot 0^{(20)}$ \\
\hline oxLDL (U/I) & - & $19 \cdot 61$ & - & $20 \cdot 24$ & - & 103 & - \\
\hline \multicolumn{8}{|l|}{ Anthropometric data } \\
\hline BMI $\left(\mathrm{kg} / \mathrm{m}^{2}\right)$ & $26 \cdot 8$ & $26 \cdot 7$ & $26 \cdot 7$ & $3 \cdot 0$ & 0.634 & 11 & $18 \cdot 5-24 \cdot 9^{(42)}$ \\
\hline Waist-to-hip ratio & 0.87 & 0.86 & 0.87 & 0.08 & 0.222 & 9 & $0 \cdot 85-1 \cdot 00^{(42)}$ \\
\hline \multicolumn{8}{|c|}{ Clinical and biochemical features } \\
\hline Total cholesterol (mм) & 4.87 & $4 \cdot 74$ & $4 \cdot 81$ & 0.887 & 0.517 & 18 & $<5.17 \dagger$ \\
\hline LDL cholesterol (mM) & $3 \cdot 32$ & $3 \cdot 28$ & $3 \cdot 30$ & 0.788 & 0.756 & 24 & $<3.38 \dagger$ \\
\hline HDL cholesterol (mм) & 0.891 & 0.865 & 0.878 & 0.209 & 0.249 & 24 & $>1.03 \dagger$ \\
\hline TAG (mM) & 1.53 & $1 \cdot 37$ & 1.45 & 0.877 & 0.545 & 60 & $<1.76 \dagger$ \\
\hline Glucose (mM) & $5 \cdot 84$ & $5 \cdot 86$ & $5 \cdot 85$ & 0.6 & 0.631 & 10 & $3.89-5.55 \dagger$ \\
\hline
\end{tabular}

$T_{0}$, time at $0 \mathrm{~min} ; T_{30}$, time at $30 \mathrm{~min}$; MDA, malondialdehyde; FRAP, ferric reducing power; DPPH, 2,2-diphenyl-1-picrylhydrazyl radical; oxLDL, oxidised LDL.

* Probability value obtained by $t$ test for dependent variables.

† Normal ranges for biochemical features were based on the recommendations of the National Cholesterol Education Program. 
Table 2. Dietary intake of the individuals measured before and after $30 \mathrm{~d}$ (Mean values and pooled standard deviations)

\begin{tabular}{|c|c|c|c|c|c|c|}
\hline Variables & $T_{0}$ & $T_{30}$ & Mean & Pooled SD & $P^{*}$ & $\begin{array}{c}\text { Dietary reference intakes } \\
\text { (United States Department of Agriculture database })^{(25)}\end{array}$ \\
\hline Energy intake (kJ) & 5922.35 & 6508.39 & 6273.98 & 2273.0 & 0.019 & $8372 \cdot 0$ \\
\hline Protein (\% of energy) & $19 \cdot 23$ & 18.03 & $18 \cdot 67$ & $25 \cdot 40$ & 0.505 & $10 \cdot 00-35 \cdot 00$ \\
\hline Fat (\% of energy) & 34.35 & $32 \cdot 24$ & 33.36 & $46 \cdot 18$ & 0.463 & $20 \cdot 00-35 \cdot 00$ \\
\hline Carbohydrate ( $\%$ of energy) & 47.41 & $49 \cdot 73$ & 48.06 & $46 \cdot 34$ & $<0.001$ & $45 \cdot 00-65 \cdot 00$ \\
\hline SFA (\% of energy) & 8.02 & 8.86 & 8.35 & 12.59 & 0.002 & $<10 \%$ of total energy ${ }^{(43)}$ \\
\hline MUFA (g) & $13 \cdot 2$ & $15 \cdot 5$ & 14.4 & $6 \cdot 7$ & 0.067 & - \\
\hline PUFA ( $\%$ of energy) & 4.7 & 4.9 & 4.8 & $6 \cdot 3$ & 0.103 & $6-10 \%$ of total energy ${ }^{(43)}$ \\
\hline Cholesterol (mg) & 193.6 & $196 \cdot 6$ & $195 \cdot 1$ & 98.7 & 0.722 & $<300 \mathrm{mg}^{(43)}$ \\
\hline Fibre (g) & $16 \cdot 00$ & $15 \cdot 20$ & $15 \cdot 62$ & 7.05 & 0.378 & $25 \cdot 00-30.00$ \\
\hline $\mathrm{Ca}(\mathrm{mg})$ & $421 \cdot 20$ & $479 \cdot 70$ & 448.85 & 255.41 & 0.064 & $1000 \cdot 00-1200 \cdot 00$ \\
\hline $\mathrm{Fe}(\mathrm{mg})$ & $6 \cdot 20$ & 6.40 & $6 \cdot 32$ & 2.90 & 0.569 & $8.00-18.00$ \\
\hline $\mathrm{Mg}(\mathrm{mg})$ & $149 \cdot 60$ & 153.80 & $150 \cdot 88$ & $60 \cdot 97$ & 0.432 & $320 \cdot 00-420 \cdot 00$ \\
\hline $\mathrm{K}(\mathrm{mg})$ & $1622 \cdot 90$ & 1655.30 & 1634.31 & 596.45 & 0.713 & $4700 \cdot 00$ \\
\hline $\mathrm{Na}(\mathrm{mg})$ & $1836 \cdot 60$ & 1938.60 & 1894.49 & $870 \cdot 18$ & 0.182 & $1200 \cdot 00-1500 \cdot 00$ \\
\hline $\mathrm{Zn}(\mathrm{mg})$ & 8.00 & $7 \cdot 70$ & 7.89 & $4 \cdot 21$ & 0.283 & $8.00-11.00$ \\
\hline Vitamin C (mg) & 94.40 & $102 \cdot 10$ & 97.04 & $91 \cdot 64$ & 0.444 & $75 \cdot 00-90.00$ \\
\hline Vitamin $B_{1}(\mathrm{mg})$ & $0 \cdot 70$ & 0.90 & 0.78 & 0.50 & 0.025 & $1 \cdot 10-1 \cdot 20$ \\
\hline Vitamin $B_{2}(\mathrm{mg})$ & 0.80 & 1.00 & 0.90 & 0.48 & 0.003 & $1.10-1.30$ \\
\hline Niacin (mg) & 14.80 & $17 \cdot 50$ & $16 \cdot 16$ & 11.88 & 0.072 & $14.00-16.00$ \\
\hline Vitamin $B_{6}(\mathrm{mg})$ & 0.60 & 0.80 & 0.68 & 0.46 & 0.020 & $1.30-1.70$ \\
\hline Vitamin A ( $\mu \mathrm{g} R E)$ & $291 \cdot 27$ & 411.54 & 360.59 & $507 \cdot 24$ & 0.195 & $700 \cdot 00-900 \cdot 00$ \\
\hline Folate $(\mu \mathrm{g})$ & $65 \cdot 70$ & 68.50 & 65.32 & $52 \cdot 98$ & 0.989 & $400 \cdot 00$ \\
\hline
\end{tabular}

$T_{0}$, time at $0 \mathrm{~min} ; T_{30}$, time at $30 \mathrm{~min} ; \mathrm{RE}$, retinol equivalents.

* Probability value obtained by $t$ test for dependent variables.

Based on the cluster analysis that was applied to the standardised values (Fig. 2), we proposed the separation of the individuals into five clusters.

All groups significantly differed according to at least one of the four biomarkers. The separation of the individuals in the

Table 3. Clinical, biochemical, major fatty acids profile and oxidative biomarkers measured in plasma of the subjects according to sex

\begin{tabular}{|c|c|c|c|}
\hline Variables & $\begin{array}{c}\text { Female } \\
(n 35)\end{array}$ & $\begin{array}{l}\text { Male } \\
(n 22)\end{array}$ & $P^{\star}$ \\
\hline Age (years) & 66 & 58 & 0.008 \\
\hline $\mathrm{MDA}(\mu \mathrm{mol} / \mathrm{l})$ & 1.4 & 1.4 & 0.736 \\
\hline $\operatorname{FRAP}(\mu \mathrm{mol} / \mathrm{l})$ & $830 \cdot 2$ & 988.4 & $<0.001$ \\
\hline DPPH (\% of inhibition) & $4 \cdot 2$ & 4.9 & 0.023 \\
\hline oxLDL (U/I) & $19 \cdot 6$ & $19 \cdot 7$ & 0.974 \\
\hline Total cholesterol (mM) & 4.85 & 4.69 & 0.455 \\
\hline LDL cholesterol (mM) & 3.34 & $3 \cdot 19$ & 0.426 \\
\hline HDL cholesterol (mм) & 0.945 & 0.765 & 0.001 \\
\hline TAG (mм) & $1 \cdot 30$ & 1.68 & 0.086 \\
\hline Glucose (mM) & $5 \cdot 74$ & 6.03 & 0.050 \\
\hline \multicolumn{4}{|l|}{ Total plasma fatty acids (\%) } \\
\hline C14:0 - myristic & 1.4 & 1.3 & 0.479 \\
\hline C16:0 - palmitic & $21 \cdot 2$ & $22 \cdot 3$ & 0.134 \\
\hline C18:0 - estearic & $6 \cdot 0$ & $6 \cdot 5$ & 0.191 \\
\hline C18: $1 n-9$ - oleic & $18 \cdot 3$ & $20 \cdot 2$ & 0.075 \\
\hline C18:2n-6 - linoleic & $30 \cdot 5$ & $27 \cdot 3$ & 0.014 \\
\hline C18:3n-3 - linolenic & $1 \cdot 6$ & 1.5 & 0.476 \\
\hline C20: $4 n-6$ - arachidonic & $8 \cdot 8$ & 8.4 & 0.620 \\
\hline C20:5n-3 - eicosapentaenoic & 0.7 & 0.7 & 0.890 \\
\hline C22: $6 n-3$ - docosahexaenoic & 1.2 & 1.3 & 0.583 \\
\hline SFA (\%) & $30 \cdot 1$ & 31.5 & 0.146 \\
\hline MUFA (\%) & 23.5 & $25 \cdot 3$ & 0.129 \\
\hline PUFA (\%) & $45 \cdot 4$ & 41.9 & 0.041 \\
\hline PI & $73 \cdot 6$ & $70 \cdot 1$ & 0.314 \\
\hline
\end{tabular}

MDA, malondialdehyde; FRAP, ferric reducing power; DPPH, 2,2-diphenyl1-picrylhydrazyl radical; oxLDL, oxidised LDL; PI, peroxidability index. ${ }^{*}$ Probability value obtained by $t$ test for independent variables. first axis was based upon their total antioxidant activity. Clusters located on the left side, which included groups $3-5$, showed a lower total antioxidant activity than the clusters located on the right side, which included groups 1 and 2. Statistical differences (Table 4) were observed for the myristic acid proportion $(P=0.044)$ between individuals who composed clusters $1(1.6 \%)$ and $5(1.0 \%)$ and for the arachidonic acid proportion $(P=0.049)$ between individuals who composed clusters $2(7.3 \%)$ and $3(10.9 \%)$. A statistically significant correlation $(r-0.33, P=0.035)$ was observed between the antioxidant activity that was measured by DPPH and peroxidability index. The separation of the individuals in the second axis was due to their oxidation that was measured by the MDA and oxLDL concentrations. Clusters located on the upper side, which included groups 2 and 3, showed greater oxidative status than clusters located on the lower side, which included groups 1, 4 and 5. Statistical differences were observed for HDL cholesterol concentration $(P=0.004)$ between individuals who composed clusters $2(0.809 \mathrm{mM})$ and $4(1.045 \mathrm{~mm})$. No statistical difference in the dietary pattern was observed among the five groups (Table 4), which included macronutrients, micronutrients and fatty acids.

\section{Discussion}

Initially, the present results showed the variation of the four oxidative stress biomarkers over the course of $30 \mathrm{~d}$. Taking into account the fact that $30 \mathrm{~d}$ is not enough time to change the oxidation stress of an organism in a population that did not change life routine and/or dietary pattern, this variation reflects the intrinsic range of these biomarkers. The mean values for the four biomarkers that were evaluated in the individuals with dyslipidaemia controlled by statins suggested that this population presented a higher oxidative status 


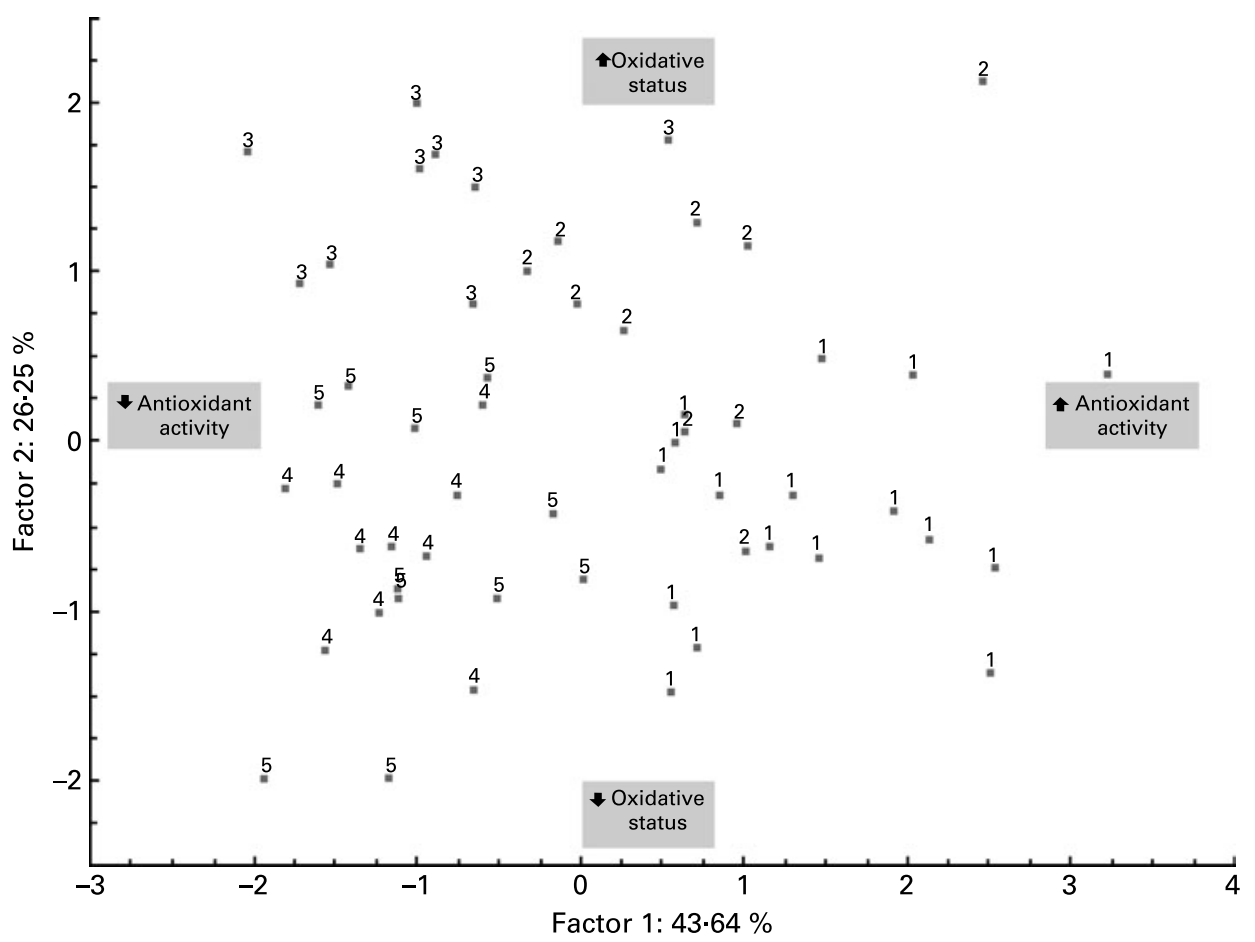

Fig. 1. Projection of the individuals $(n 57)$ designed by their cluster numbers $(1-5)$ on the factor plane $(1 \times 2)$. The active variables that were selected were percentage of inhibition as measured by 2,2-diphenyl-1-picrylhydrazyl and ferric reducing ability power values, which are presented in the first axis as antioxidant activity, oxidised LDL and malondialdehyde concentration, which are presented in the second axis as oxidative status.

and a higher oxidative susceptibility than those presented by normolipidaemic subjects who have been reported in the literature.

MDA is produced by the decomposition of hydroperoxides that are formed from the PUFA oxidation that is mediated by free radicals or by the reaction between hydroxyl radicals and acrolein $^{(26)}$. MDA can also modify apo $\mathrm{B}^{(27)}$, making this phenomenon the basis of atherogenicity. Healthy plasma MDA values change approximately about $1.0 \mu \mathrm{mol} / \mathrm{l}^{(28)}$. The mean concentration of MDA that was observed in the present

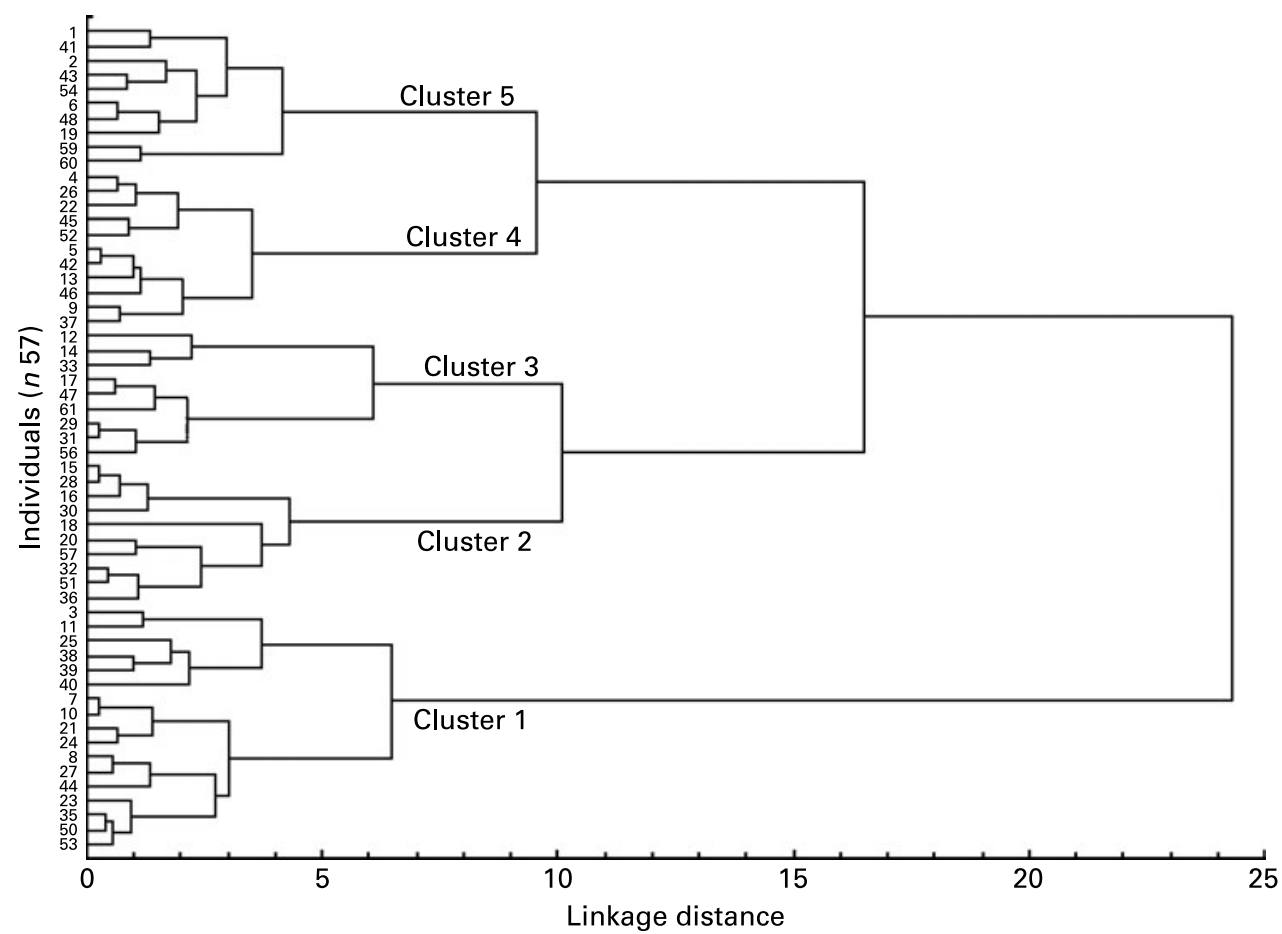

Fig. 2. Separation of the individuals ( $n 57$ ) according to the cluster analysis (tree-clustering diagram) applied based on Ward's method and Euclidean distances. 
Table 4. Mean values of age, plasma oxidative stress biomarkers, fatty acids proportion, biochemical parameters, nutrient intake and statin dose that was observed for each cluster presented in Fig. 2

(Mean values and pooled standard deviations)

\begin{tabular}{|c|c|c|c|c|c|c|c|}
\hline Variables & 1 & 2 & 3 & 4 & 5 & Pooled SD & $P^{*}$ \\
\hline$n$ & 17 & 10 & 9 & 11 & 10 & - & - \\
\hline Age (years) & $66 \cdot 2$ & $66 \cdot 1$ & $52 \cdot 0$ & 64.9 & $65 \cdot 0$ & $11 \cdot 8$ & 0.081 \\
\hline$F(\%) n$ & (53) 9 & $(60) 6$ & (63) 5 & (80) 8 & (71) 5 & - & - \\
\hline $\operatorname{MDA}(\mu \mathrm{mol} / \mathrm{l})$ & $1.4^{\mathrm{a}}$ & $1.4^{\mathrm{a}}$ & $1.8^{b}$ & $1.4^{\mathrm{a}}$ & $1 \cdot 1^{\mathrm{c}}$ & 0.3 & 0.001 \\
\hline $\operatorname{FRAP}(\mu \mathrm{mol} / \mathrm{l})$ & $1026 \cdot 8^{\mathrm{a}}$ & $975 \cdot 6^{a}$ & $792 \cdot 1^{\mathrm{b}}$ & $716 \cdot 5^{b}$ & $798 \cdot 4^{b}$ & $168 \cdot 7$ & 0.017 \\
\hline DPPH (\% of inhibition) & $5 \cdot 6^{\mathrm{a}}$ & $5 \cdot 1^{a}$ & $3.7^{b}$ & $3.5^{\mathrm{b}}$ & $3.5^{\mathrm{b}}$ & $1 \cdot 2$ & $<0.001$ \\
\hline oxLDL (U/I) & $4 \cdot 26^{a}$ & $32.4^{\mathrm{b}}$ & $45 \cdot 1^{\mathrm{b}}$ & $7 \cdot 0^{\mathrm{a}}$ & $29 \cdot 4^{b}$ & $21 \cdot 2$ & $<0.001$ \\
\hline $14: 0(\%)$ & $1 \cdot 60^{\mathrm{a}}$ & $1 \cdot 32^{\mathrm{a}, \mathrm{b}}$ & $1 \cdot 26^{a, b}$ & $1 \cdot 38^{\mathrm{a}, \mathrm{b}}$ & $1.04^{\mathrm{b}}$ & 0.5 & 0.044 \\
\hline $16: 0(\%)$ & $22 \cdot 1$ & $22 \cdot 3$ & $20 \cdot 4$ & $21 \cdot 8$ & $20 \cdot 7$ & 2.5 & 0.289 \\
\hline $18: 0(\%)$ & 5.57 & 6.41 & $6 \cdot 23$ & 6.47 & 6.43 & 1.2 & 0.629 \\
\hline $18: 1 n-9(\%)$ & $19 \cdot 8$ & $20 \cdot 3$ & $18 \cdot 4$ & $17 \cdot 0$ & $18 \cdot 7$ & 3.4 & 0.648 \\
\hline $18: 2 n-6(\%)$ & 28.4 & $30 \cdot 1$ & 28.3 & 30.5 & 29.9 & $4 \cdot 2$ & 0.237 \\
\hline $18: 3 n-3(\%)$ & $1 \cdot 70$ & 1.47 & 1.70 & 1.67 & 1.27 & 0.5 & 0.299 \\
\hline $20: 4 n-6(\%)$ & $8 \cdot 2^{a b}$ & $7 \cdot 3^{\mathrm{a}}$ & $10.9^{\mathrm{b}}$ & $9 \cdot 6^{\mathrm{ab}}$ & $8 \cdot 6^{\mathrm{ab}}$ & $2 \cdot 4$ & 0.050 \\
\hline $20: 5 n-3(\%)$ & 0.69 & 0.52 & 0.77 & 0.69 & 0.65 & 0.3 & 0.905 \\
\hline $22: 6 n-3(\%)$ & 1.09 & 1.03 & $1 \cdot 28$ & 1.06 & 1.32 & 0.5 & 0.337 \\
\hline SFA (\%) & $30 \cdot 6$ & 31.4 & 29.9 & $30 \cdot 7$ & 29.9 & 3.1 & 0.612 \\
\hline MUFA (\%) & $25 \cdot 2$ & $25 \cdot 3$ & $23 \cdot 1$ & $22 \cdot 2$ & $24 \cdot 0$ & 3.7 & 0.870 \\
\hline PUFA (\%) & 43.0 & 42.5 & $45 \cdot 8$ & $45 \cdot 8$ & 44.8 & 5.5 & 0.812 \\
\hline Peroxidability index & 69.9 & 66.5 & 79.4 & $75 \cdot 8$ & 73.5 & $11 \cdot 1$ & 0.632 \\
\hline Cholesterol (mм) & $4 \cdot 6$ & 4.78 & 5.03 & $5 \cdot 14$ & 4.53 & 0.781 & 0.063 \\
\hline LDL (mм) & 2.96 & 3.32 & 3.65 & 3.56 & 3.22 & 0.681 & 0.140 \\
\hline $\mathrm{HDL}(\mathrm{mm})$ & $0.842^{a}$ & $0.809^{a}$ & $0.845^{\mathrm{a}, \mathrm{b}}$ & $1.045^{\mathrm{b}}$ & $0.878^{a, b}$ & 0.203 & 0.004 \\
\hline Glucose (mM) & $6 \cdot 12$ & 5.93 & 5.74 & $5 \cdot 75$ & 5.58 & 0.55 & 0.174 \\
\hline TAG (mM) & 1.84 & 1.49 & 1.23 & 1.23 & 1.01 & 0.82 & 0.868 \\
\hline BMI $\left(\mathrm{kg} / \mathrm{m}^{2}\right)$ & $27 \cdot 1$ & $25 \cdot 2$ & $28 \cdot 1$ & $26 \cdot 4$ & $26 \cdot 8$ & 3.0 & 0.384 \\
\hline Hip-to-waist ratio & 0.9 & 0.9 & 0.8 & 0.8 & 0.9 & 0.1 & 0.628 \\
\hline Energy $(\mathrm{kJ})$ & 6091.47 & $6412 \cdot 95$ & $6188 \cdot 16$ & $5761 \cdot 19$ & 6603.83 & $2022 \cdot 25$ & 0.518 \\
\hline Protein $(\mathrm{g})$ & $66 \cdot 4$ & 69.5 & $65 \cdot 1$ & 68.2 & $74 \cdot 2$ & 29.5 & 0.808 \\
\hline Fat (g) & $52 \cdot 7$ & $57 \cdot 6$ & 54.5 & $52 \cdot 6$ & 54.5 & 23.1 & 0.289 \\
\hline SFA (g) & $16 \cdot 9$ & 14.5 & $12 \cdot 0$ & 13.5 & $13 \cdot 1$ & $7 \cdot 6$ & 0.325 \\
\hline MUFA $(\mathrm{g})$ & 14.5 & $16 \cdot 4$ & $12 \cdot 9$ & $13 \cdot 8$ & $13 \cdot 2$ & $6 \cdot 7$ & 0.325 \\
\hline PUFA (g) & 8.6 & $7 \cdot 6$ & $6 \cdot 8$ & $6 \cdot 6$ & $8 \cdot 3$ & 3.8 & 0.831 \\
\hline Cholesterol (mg) & $169 \cdot 9$ & $187 \cdot 1$ & $215 \cdot 1$ & $219 \cdot 7$ & 174.9 & 98.7 & 0.511 \\
\hline Carbohydrate (g) & 178.7 & $184 \cdot 0$ & $182 \cdot 0$ & 157.5 & $199 \cdot 7$ & $57 \cdot 2$ & 0.738 \\
\hline Fibre (g) & $16 \cdot 4$ & $14 \cdot 2$ & $14 \cdot 6$ & 13.9 & $18 \cdot 8$ & $6 \cdot 4$ & 0.603 \\
\hline $\mathrm{Ca}(\mathrm{mg})$ & $433 \cdot 2$ & $463 \cdot 8$ & 385.5 & 452.9 & $562 \cdot 6$ & 239.8 & 0.696 \\
\hline $\mathrm{Fe}(\mathrm{mg})$ & 5.5 & $6 \cdot 6$ & 6.5 & $5 \cdot 7$ & $7 \cdot 6$ & $2 \cdot 6$ & 0.217 \\
\hline $\mathrm{Mg}(\mathrm{mg})$ & $140 \cdot 6$ & $142 \cdot 4$ & 148.4 & 141.6 & 187.9 & $56 \cdot 7$ & 0.437 \\
\hline$P(\mathrm{mg})$ & $672 \cdot 9$ & 694.7 & 695.4 & 691.8 & 814.0 & 246.4 & 0.623 \\
\hline $\mathrm{K}(\mathrm{mg})$ & $1577 \cdot 8$ & $1582 \cdot 1$ & $1524 \cdot 0$ & $1599 \cdot 8$ & $1869 \cdot 2$ & $535 \cdot 0$ & 0.834 \\
\hline $\mathrm{Na}(\mathrm{mg})$ & $1882 \cdot 3$ & $1912 \cdot 2$ & $1874 \cdot 1$ & $1845 \cdot 7$ & 1828.5 & 774.6 & 0.744 \\
\hline $\mathrm{Zn}(\mathrm{mg})$ & $6 \cdot 5$ & $8 \cdot 8$ & 8.4 & $8 \cdot 2$ & $7 \cdot 3$ & 3.9 & 0.142 \\
\hline$M n(g)$ & 1.4 & 1.5 & 1.8 & 1.4 & 1.8 & 0.8 & 0.496 \\
\hline Vitamin C (mg) & $100 \cdot 9$ & $95 \cdot 2$ & $71 \cdot 7$ & $86 \cdot 8$ & $138 \cdot 2$ & $82 \cdot 8$ & 0.885 \\
\hline Vitamin $B_{1}(\mathrm{mg})$ & 0.8 & 0.9 & 0.7 & 0.6 & 0.8 & 0.4 & 0.328 \\
\hline Vitamin $B_{2}(\mathrm{mg})$ & 0.9 & 1.0 & 1.0 & 0.8 & 0.9 & 0.4 & 0.341 \\
\hline Niacine (mg) & $15 \cdot 1$ & 13.5 & $18 \cdot 4$ & $15 \cdot 9$ & $16 \cdot 7$ & $9 \cdot 1$ & 0.831 \\
\hline Vitamin $\mathrm{B}_{6}(\mathrm{mg})$ & 0.6 & 0.7 & 0.8 & 0.6 & 0.7 & 0.4 & 0.489 \\
\hline Vitamin A ( $\mu \mathrm{g} R E)$ & $1559 \cdot 5$ & $966 \cdot 7$ & $1617 \cdot 7$ & 828.5 & 1311.7 & $1550 \cdot 9$ & 0.745 \\
\hline Folate $(\mu \mathrm{g})$ & $56 \cdot 6$ & $72 \cdot 8$ & 64.0 & $54 \cdot 1$ & $84 \cdot 2$ & $44 \cdot 1$ & 0.722 \\
\hline Statin doses $(\mathrm{mg} / \mathrm{d})$ & $20 \cdot 0$ & $14 \cdot 3$ & $25 \cdot 7$ & $16 \cdot 7$ & $23 \cdot 3$ & $13 \cdot 6$ & 0.545 \\
\hline
\end{tabular}

MDA, malondialdehyde; FRAP, ferric reducing power; DPPH, 2,2-diphenyl-1-picrylhydrazyl radical; oxLDL, oxidised LDL; RE, retinol equivalents. $a, b, c$ Mean values in the same row with different superscript letters are significantly different $(P<0.05)$.

* Probability value obtained by ANOVA.

study for the individuals with dyslipidaemia controlled by statins was 1.4 (SD 0.4) $\mu \mathrm{mol} / \mathrm{l}$. This value was between those reported by Agarwal \& Chase ${ }^{(29)}$ for healthy, normolipidaemic individuals (1.09 (SD 0.43) $\mu \mathrm{mol} / \mathrm{l}$ ) and those reported by Jenkins et al. ${ }^{(27)}$ for older, hyperlipidaemic subjects (1.6 (SD 0.1) $\mu \mathrm{mol} / \mathrm{l})$.

Several factors could explain the higher oxidative status and oxidative susceptibility that was observed in our patients.
Elevated glucose concentrations can increase the activity of some enzymes that are involved with lipid oxidation, such as 12/15-lipoxygenase and the NADPH oxidases. In addition, glucose can react with amino groups and lipids to produce advanced glycation end products. These advanced glycation end products are associated with higher reactive oxygen species production, which increases MDA concentration $^{(11,30-32)}$. The antioxidant effect of some of the 
proteins that are present in HDL cholesterol, such as paraoxonase-1, is widely recognised ${ }^{(33-35)}$. Paraoxonase- 1 is an esterase that is associated with HDL cholesterol, which is able to hydrolyse oxidised lipids and, consequently, reduce the oxidative stress in lipoproteins, macrophages and atherosclerotic lesions ${ }^{(34)}$. Several studies have shown that paraoxonase-1 protects LDL cholesterol and HDL cholesterol against oxidation and destroys biologically active oxidised lipids in lipoproteins and arterial walls. Its association with HDL cholesterol is a prerequisite for maintaining normal serum activity of the enzyme ${ }^{(7)}$. Thus, the high glucose concentration $(5.85(\mathrm{SD} 0.6) \mathrm{mM})$, which indicates a pre-diabetic condition for these individuals, associated with the low values of HDL cholesterol (0.818 (SD 0.209) mM), could have both contributed to the higher oxidative stress that was observed in this population.

Multivariate statistical analysis, among a wide possibility of applications, allows the visualisation of a large number of associations at the same time and some load. In addition, it is possible to group individuals after data collection and start an interventional protocol for the newly formed groups. For example, it has been emphasised the importance of the baseline concentrations of antioxidants in studies involving oxidative biomarkers $^{(10,36,37)}$. Using multivariate statistics, it is possible to group the individuals according to their baseline concentrations as evaluated by more than three criteria at the same time, as we had already suggested ${ }^{(38)}$, and to examine the antioxidant intervention in each group. With regard to in vivo oxidation research, multivariate statistical methods will offer an additional contribution, since more than a few biomarkers are necessary to diagnose oxidative status or oxidative susceptibility ${ }^{(39)}$.

In the present study, we first tried to evaluate whether the individuals could be classified according to their oxidative stress, and after to check whether some dietary component could be associated with this classification. Multivariate analysis showed to be a very useful tool for classifying these individuals according to their scores obtained by four biomarkers. However, no association was observed between the oxidative stress classification and the food intake of these patients. The failure to identify an association could be attributed to the low size sample ( $n$ 57), interviewer bias, differences in the food databases that were used to convert the food intake into nutrient intake ${ }^{(40)}$ and blood collection in fasting instead of postprandial state ${ }^{(41)}$. Although the sample size was low, individuals showed a large range for their nutrient intake. Thus, we suppose that other factors, which are mainly associated with genetic aspects, can exert a much higher effect on these biomarkers than the diet. Stephens et $a l^{(12)}$ suggested that oxidative stress can be better observed by biomarkers in individuals who are exposed to gene-environment interactions, such as smokers who carry the $\varepsilon 4$ allele of the apo E gene. The lack of any significant association between oxidative biomarkers and the nutrient intake in the present study might have been different if some genetic variants were included in the investigation.

The first PC (horizontal axis, Fig. 1) separated the individuals according to their total plasma antioxidant activity. A high correlation was observed between the FRAP and DPPH assays $(r+0.73, P<0.01)$. It was not surprising, since both methods measured the ability of the almost same compounds (bilirubin, uric acid, ascorbic acid, carotenoids, tocopherols, flavonoids and others) to donate electrons or hydrogen to the radicals, $\mathrm{Fe}^{3+}$ and $\mathrm{DPPH}$, respectively. A higher proportion of myristic acid (C14:0) and a lower proportion of arachidonic acid (C20:4n-6) were observed in the individuals on the right side, where the clusters presented higher total plasma antioxidant activity. This plasma composition represents a worse substrate to oxidation by reactive species because of its lower number of double bonds. It was also observed a negative significant correlation between DPPH and the peroxidability index values of these patients. Although the fatty acid composition of adipose tissue and blood can be used as biomarker of fatty acid intake ${ }^{(40)}$, this proportion can be also due to the desaturase activities, which are the limiting factors in the biosynthesis of highly unsaturated, long-chain fatty acids, such as arachidonic acid, from their percursors ${ }^{(8)}$. Competition between metabolic pathways may lead to changes in fatty acid composition that are not directly related to diet. Since the blood samples were collected during fasting state, fatty acids that were derived from the diet or biosynthesised, both contributed to the profile that was observed in our patients. Based on the fact that no associations were observed between diet intake (including fatty acids) and oxidative stress, it could be suggested that fatty acid synthesis would have a more extensive effect on oxidative susceptibility than the fatty acids from the diet. It is possible that the diet effect in this population on oxidative stress, which was not submitted to a diet treatment, could only be visualised under postprandial conditions, as before suggested by Sies et al. ${ }^{(41)}$.

With regard to the second PC (vertical axis, Fig. 1), individuals were separated according to their oxidative stress that was measured by oxLDL and MDA concentrations. Clusters located in the upper side, which showed a higher oxidative stress, presented lower HDL cholesterol concentrations than clusters located in the lower side. As reported for the first PC, there were no additional differences, including the dietary pattern, among the clusters in this second axis. Many studies have shown the role of HDL cholesterol as antioxidant. Paraoxonase-1 has been shown to inhibit cholesterol influx by reducing the formation of oxLDL, which increases the breakdown of specific oxidised lipids in oxLDL and decreases macrophage uptake of oxLDL ${ }^{(33)}$. The present results suggest that the antioxidant activity of HDL cholesterol particles can be better observed by measuring oxidative status (MDA and oxLDL) than antioxidant activity (DPPH and FRAP).

In summary, the multivariate techniques that were applied in the present study allowed individuals to be grouped according to their oxidative stress as measured by four biomarkers, which are all clinically relevant. Based on this multivariate approach, we can suggest that fatty acid synthesis and HDL cholesterol concentration seem to exert a more extensive effect on the oxidative conditions of the individuals with dyslipidaemia controlled by statins than food intake. However, studies involving some gene polymorphic evaluations for in vivo oxidative biomarkers that are associated by multivariate analysis may be necessary to explain the reason that it was not possible to observe any effect of diet on oxidative stress in these individuals. 


\section{Acknowledgements}

The present study was financially supported by the FAPESP (07/01476-8; 08/00482-7 and 08/10 826-5). The authors declare no conflict of interest. The author's responsibilities were as follows: P. B. B. was responsible for data collection/ interpretation and manuscript preparation; C. O. F. contributed to the data collection; D. S. P. A. helped in the oxLDL analysis; M. C. B. critically reviewed the manuscript; I. A. C. designed the study, prepared the manuscript and obtained funding from FAPESP.

\section{References}

1. Jones DP (2006) Redefining oxidative stress. Antioxid Redox Signal 8, 1865-1879.

2. Ursini F \& Sevanian A (2002) Postprandial oxidative stress. Biol Chem 383, 599-605.

3. Hansel B, Nicolle C \& Lalanne F (2007) Effect of low-fat, fermented milk enriched with plant sterols on serum lipid profile and oxidative stress in moderate hypercholesterolemia. Am J Clin Nutr 86, 790-796.

4. Papaharalambus CA \& Griendling KG (2007) Basic mechanisms of oxidative stress and reactive oxygen species in cardiovascular injury. Trends Cardiovasc Med 17, 48-52.

5. Esterbauer H, Gebicki J, Puhl H, et al. (1992) The role of lipid peroxidation and antioxidants in oxidative modification of LDL. Free Radic Biol Med 13, 341-390.

6. Berliner JA \& Heinecke JW (1996) The role of oxidized lipoproteins in atherogenesis. Free Radic Biol Med 20, 707-727.

7. Girona J, Manzanares JM, Marimón F, et al. (2008) Oxidized to non-oxidized lipoprotein ratios are associated with arteriosclerosis and the metabolic syndrome in diabetic patients. Nutr Metab Cardiovasc Dis 18, 380-387.

8. Barja G (2002) Rate of generation of oxidative stress-related damage and animal longevity. Free Rad Biol Med 33, $1167-1172$.

9. Kaliora AC, Dedoussis GVZ \& Schmidt H (2006) Dietary antioxidants in preventing atherogenesis. Atherosclerosis 187, $1-17$.

10. Kaliora AC \& Dedoussis GVZ (2007) Natural antioxidant compounds in risk factors for CVD. Pharmacol Res 56, 99-109.

11. Mori TA, Woodman RJ, Burke V, et al. (2003) Effect of eicosapentaenoic acid and docosahexaenoic acid on oxidative stress and inflammatory markers in treated-hypertensive type 2 diabetic subjects. Free Rad Biol Med 35, 772-781.

12. Stephens JW, Bain SC \& Humphries SE (2008) Gene-environment interaction and oxidative stress in cardiovascular disease. Atherosclerosis 200, 229-238.

13. Blumberg JB \& Frei B (2007) Why clinical trials of vitamin E and cardiovascular diseases may be fatally flawed. Commentary on the relationship between dose of vitamin $\mathrm{E}$ and suppression of oxidative stress in humans. Free Rad Biol Med 43, 1374-1376.

14. Capitani CD, Carvalho ACL, Rivelli DP, et al. (2009) Evaluation of natural and synthetic compounds according to their antioxidant activity using a multivariate approach. Eur J Lipid Sci Technol (epublication ahead of print version 31 March 2009).

15. Nutriquanti (2007) Sistema de acompanhamento do consumo alimentar. (Accompaniment System do Fuel Consumption; version 1). http://www.nutriquanti.com.br

16. Friedwald WT, Levy R \& Fredrickson DS (1972) Estimations of serum low density lipoprotein cholesterol without use of preparative ultracentrifuge. Clin Chem 18, 499-502.
17. Folch J, Lees M \& Stanley SGH (1957) A simple method for the isolation and purification of total lipids. J Biol Chem 226, 497-509.

18. Hartman L \& Lago BCA (1973) Rapid preparation of fatty acid methyl esters from lipids. Lab Pract 22, 475-477.

19. Hsu HC, Lee YT \& Chen MF (2001) Effects of fish oil and vitamin $\mathrm{E}$ on the antioxidant defense system in diet-induced hypercholesterolemic rabbits. Prostaglandins Other Lipid Mediat 66, 99-108.

20. Chrzczanowicz J, Gawron A, Zwolinska A, et al. (2008) Simple method for determining human serum 2,2-diphenyl1-picryl-hydrazyl (DPPH) radical scavenging activity - possible application in clinical studies on dietary antioxidants. Clin Chem Lab Med 46, 342-349.

21. Benzie IFF \& Strain JJ (1999) Ferric reducing/antioxidant power assay: direct measure of total antioxidant activity of biological fluids and modified version for simultaneous measurement of total antioxidant power and ascorbic acid concentration. Anal Biochem 239, 70-76.

22. Faulin TES, Sena KCM, Telles AER, et al. (2008) Validation of a novel ELISA for measurement of electronegative LDL. Clin Chem Lab Med 46, 1769-1775.

23. Cheng GW, Wu HL \& Huang YL (2008) Simultaneous determination of malondialdehyde and ofloxacin in plasma using an isocratic high-performance liquid chromatography/fluorescence detection system. Anal Chim Acta 616, 230-234.

24. National Cholesterol Education Program (NCEP) (2001) Expert Panel on Detection, Evaluation, and Treatment of High Blood Cholesterol in Adults (Adult Treatment Panel III). Third Report of the National Cholesterol Education Program (NCEP) Expert Panel on Detection, Evaluation, and Treatment of High Blood Cholesterol in Adults (Adult Treatment Panel III) Final Report. Bethesda, MD: NIH Publication, pp. 1-28, available at http://www.americanheart.org.htm

25. Institute of Medicine (2004) Food and Nutrition Board. Dietary Reference Intakes: Table for Vitamins, Minerals and Macronutrients; Organized by Age and Gender. Washington, DC: National Academies of Science, available at http://www. fnic.nal.usda.gov

26. Lykkesfeldt J (2007) Malondialdehyde as biomarker of oxidative damage to lipids caused by smoking. Clin Chim Acta 380, 50-58.

27. Jenkins DJA, Kendall CWC, Marchie A, et al. (2008) Almonds reduce biomarkers of lipid peroxidation in older hyperlipidemic subjects. J Nutr 138, 908-913.

28. Del Rio D, Stewart AJ \& Pellegrini N (2005) A review of recent studies on malondialdehyde as toxic molecule and biological marker of oxidative stress. Nutr Metab Cardiovasc Dis 15, 316-328.

29. Agarwal R \& Chase SD (2002) Rapid, fluorimetric-liquid chromatography determination of malondialdehyde in biological samples. J Chromatogr Biomed Appl 775, 121-126.

30. Lambeth JD (2007) Nox enzymes, ROS, and chronic disease: an example of antagonistic pleiotropy. Free Rad Biol Med 43, 332-347.

31. Parthasarathy S, Litvinov DL, Selvarajan K, et al. (2008) Lipid peroxidation and decomposition - conflicting roles in plaque vulnerability and stability. Biochim Biophys Acta 1781, 221-231.

32. Rees MD, Kennett EC, Whitelock JM, et al. (2008) Oxidative damage to extracellular matrix and its role in human pathologies. Free Radic Biol Med 44, 1973-2001.

33. Aviram M (2004) Introduction to the serial review on paraoxonases, oxidative stress, and cardiovascular diseases. Free Radic Biol Med 37, 1301-1303.

34. Fuhrman B, Volkova N \& Aviram M (2006) Postprandial serum triacylglycerols and oxidative stress in mice after consumption 
of fish oil, soy oil or olive oil: possible role for paraoxonase-1 triacylglycerol lípase-like activity. Nutrition 22, 922-930.

35. Negre-Salvayre A, Dousset N, Ferretti G, et al. (2006) Antioxidant and cytoprotective properties of high-density lipoproteins in vascular cells. Free Radic Biol Med 41, 1031-1040.

36. Griendling KK \& FitzGerald GA (2003) Oxidative stress and cardiovascular injury. Part II: animal and human studies. Circulation 108, 1912-1916.

37. Block G, Jensen CD, Morrow JD, et al. (2008) The effect of vitamins $\mathrm{C}$ and $\mathrm{E}$ on biomarkers of oxidative stress depends on baseline level. Free Rad Biol Med 45, 377-384.

38. Castro IA, Monteiro VCB, Barroso LP, et al. (2007) Effect of eicosapentaenoic/docosahexaenoic fatty acids and soluble fibers on blood lipids of individuals classified into different levels of lipidemia. Nutrition 23, 127-137.
39. Prior RL \& Cao G (1999) In vivo total antioxidant capacity: comparison of different analytical methods. Free Rad Biol Med 27, 1173-1181.

40. Hodson L, Skeaff CM \& Fielding BA (2008) Fatty acid composition of adipose tissue and blood in humans and its use as a biomarker of dietary intake. Prog Lipid Res 47, 348-380.

41. Sies H, Stahi W \& Sevanian A (2005) Nutritional, dietary and postprandial oxidative stress. J Nutr 135, 969-972.

42. World Health Organization (2000) Obesity: Preventing and Managing the Global Epidemic. Joint WHO Consultation. WHO Technical Report Series no. 894. Geneva: WHO.

43. World Health Organization (2003) Diet, Nutrition and the Prevention of Chronic Diseases. Joint WHO/FAO Expert Consultation. WHO Technical Report Series no. 916. Geneva: WHO. 